\title{
Dampak Special 301 terhadap Industri Rekaman Indonesia
}

\author{
Hendra Tanu Atmadja
}

\begin{abstract}
The United States' strong commitment to global protection of intellectual property rights is rooted in its goal to preserve or regain the competitiveness and dominance of United States exports. In recent years, the United States has been experiencing significant and growing trade imbalances with its trading partners. The development of the Section 301 provisions in the Omnibus Trade and Competitiveness Act of 1988 ("Trade Act") over the past twenty years reflects the United States' commitment toward intermational intellectual property protection. Reacting to GATT's inability to ensure prompt action on complaints from the United States involving proliferating bilateral and free trade agreements, Congress created Section 301 as part of the 1974 Trade Act. Subsequently in 1984, recognizing the lack of intellectual property profection in other countries and the billions dollars lost by the United States intellectual property rights holders, Congress amended Section 301 to specifically address these issues. The 1984 Trade Act authorized the president to impose. trade sanctions against any country that did not provide adequate intellectual property protection and engaged in "unreasonable and unjustifiable" trade practices. The 1988 Trade Act further amended Section 301 by creating Special 301 provisions, and by granting the United States Trade Representative ("USTR") authority to act on behalf of the interests of the United States intellectual property rights holders.
\end{abstract}

\section{Pendahuluan}

Perkembangan Section 301 dalam Omnibus Trade and Competitiveness Act of 1988 (Trade Act) selama dua puluh tahun lebih mencerminkan komitmen Amerika Serikat terhadap perlindungan hak kekayaan intelektual secara global. Reaksi terhadap ketidakmampuan GATT untuk menjamin tindakan yang serba cepat dalam menghadapi keluhan-keluhan Amerika Serikat yang banyak melakukan perjanjian bilateral dan perjanjian perdagangan bebas. Kongres Amerika Serikat mencipta Section 301 sebagai bagian dari Trade Act 1984. Selanjutnya pada tahun 1984, kurangnya perlindungan terhadap kekayaan intelektual di negara-negara lain dan kerugian yang bernilai ratusan juta yang dialami oleh para pemegang hak kekayaan intelektual di Amerika Serikat. Kongres mengamandemen Section 301 yang secara khusus menyampaikan isu-isu di atas. Trade Act 1984 
memberi kuasa kepada Presiden Amerika untuk menjatuhkan sanksi-sanksi perdagangan kepada setiap negara yang tidak memberi perlindungan kekayaan intelektual secara memadai, serta terlibat dalam praktekpraktek perdagangan yang "unresasonable and unjustifiable?. Trade Act 1998 lebih lanjut mengamandemen Section 301 dengan membuat ketentuan-ketentuan Special 301 , dengan memberikan kekuasaan kepada USTR (United States Trade Representative) untuk melindungi kepentingan-kepentingan para pemegang hak atas hak kekayaan intelektual Amerika Serikat.

Ketentuan-ketentuan Special 301 dalam Trade Act 1988, memusatkan perhatian pada praktek-praktek perdagangan internasional yang tidak sehat yang berkenaan dengan hak kekayaan intelektual. "Special 301" dinamakan sedemikian rupa untuk membedakan dari ketentuan-ketentuan "Section 301" yang bersifat umum. Tujuannya ialah untuk memberi perlindungan kepada hak-hak kekayaan intelektual Amerika Serikat di luar negeri. Menyadari bahwa "pertindungan hak kekayaan intelektual internasional adalah vital bagi persaingan perusahaan-perusahaan Amerika Serikat yang bergantung kepada perlindungan hak kekayaan intelektual. ${ }^{\prime}$ Trade Act 1988 telah memberi tekanan bahwa perdagangan internasional Amerika Serikat bergantung pada perlindungan terhadap hak-hak kekayaan intelektualnya, dan harus pula menjamin adanya akses pasar yang wajar dan adil di negara-negara lain guna melindungi kepentingan-kepentingan ekonomi Amerika Serikat secara global. ${ }^{2}$

Berdasarkan ketentuan Special 301, United States Trade Representative memiliki beberapa tanggung jawab, misalnya, selambat-lambatnya pada tiap-tiap tanggal 31 Maret setiap tahunnya, USTR (United States Trade Representative) harus menyampaikan laporan National Trade Estimate tahunan kepada Presiden, Senate Finance Committee serta komite-komite DPR yang terkait, ${ }^{3}$ tujuannya adalah untuk mengidentifikasi dan menganalisis tindakan-tindakan, kebijakan-kebijakan atau praktek-praktek perdagangan negara-negara asing, yang dapat mengakibatkan kendalakendala yang besar terhadap akses pasar atau dapat menimbulkan distorsi terhadap ekspor barang-barang atau jasa-jasa Amerika Serikat. ${ }^{4}$ Barang-barang dan jasa-jasa yang dilindungi, antara lain, adalah merek dagang, paten dan hak cipta yang berlisensi atau yang diekspor oleh perusahaan-perusahaan Amerika Serikat. ${ }^{5}$ Selanjutnya, USTR (Untied States Trade Representative) dalam laporan National Trade Estimnate harus membuat analisis dan estimasi terhadap dampak dari tindakantindakan, kebijakan-kebijakan dan praktekpraktek terhadap perdagangan Amerika Serikat. $^{6}$

\footnotetext{
${ }^{1}$ Omnibus Trade and Competitiveness Act of 1988 1303(a)(1)(A).

2/bid., 1303(a)(1)(B).

319 U.S.C. 2241 (6)(1988).

419 U.S.C. 2241 (a)(1)(A)(1)(1988).

519 U.S.C. 2241 (a)(1)(A)(I)(1988).

${ }^{\circ} 19$ U.S.C. 2241 (a)(I)(B)(1988).
} 
Section 301 dan Tingkat Pelanggaran HKI di Bèberapa Negara

Menurut laporan tahunan Special 3017 yang dikeluarkan oleh Kantor Perwakilan Perdagangan Amerika Serikat (USTR - United States Trade Representative), Indonesia sebelum tahun 2000 merupakan satu-satunya negara ASEAN yang masih masuk ke dalam peringkat Priority List (daftar negara yang menjadi prioritas untuk diawasi) untuk kasuskasus pelanggaran HKI. Kedudukan ini setingkat dengan negara-negara lain seperti Bulgaria, Israel, Cina, Malaysia, Brunei Darusalam dan Afrika Selatan. Indonesia, sejak 1995 sudah dimasukkan ke dalam kategori Priority Watch List, suatu peringkat di mana pelanggaran HKI tergolong berat, sehingga Amerika Serikat merasa perlu memprioritaskan pengawasannya terhadap pelanggaran $\mathrm{HKI}$, demikian pula dapat berakibat timbulnya retaliasi di bidang ekonomi. Indonesian dituding seabgai surga pembajakan hak cipta rekaman musik dan hiburan. Sering dijumpai bahwa hampir di seluruh pasar didominasi oleh produk-produk CD dan VCD bajakan.
Diperkirakan sekitar $99 \%$ film VCD yang beredar di pasar Indonèsia adalah produk bajakan. Kawasan Pasar Glodok di Jakarta, misalnya, peredaran CD dan VCD bajakan tiap hari bisa mencapai 1.000 .000 keping. Padahal jumlah CD dan VCD asli yang beredar di pasar itu hanya berkisar 400.000 keping per bulannya.

Menurut data IIPA (Intemational Intellectual Property Alliance) tahun 2000, pelanggaran terhadap HKI khususnya hak cipta untuk tingkat dunia selama tahun 2000, Indonesia menempati posisi ke enam. Akibat pelanggaran tersebut, industri rekaman Amerika Serikat mengalami kerugian sebesar US\$174,6 juta pada tahun 2000.

Sejak tahun 1988, berdasarkan ketentuan Special Act 301, U.S. Trade Representative mendapat kewenangan unituk mengevaluasi negara-negara mitra dagang Amerika Serikat yang dianggap telah merugikan dan melanggar Hak Kekayaan Intelektual milik warga Amerika Serikat, kemudian menerapkan sanksi dagang bagi negara yang bersangkutan.

Mulai awal 1980an, sejumlah asosiasi industri Amerika telah mempersiapkan laporan tentang klaim yang diajukan sebagai akibat kerugian yang dialami pelanggaran HKI

7IP ASIA, Intellectual Property, Marketing and Communications Law, Vol. 9, No. 9, (NOvember 1996), hal.23. Setiap tahun, menurut Section 182, Trade Act Tahun 1974, sebagaimana yang telah diamandemen oleh Omnibus Trade Act Tahun 1988 (disebut Special 301), US Trade Representative (USTR) meminta masukan dari publik secara tertulis yang menyangkut "tindakan, kebijakan dan praktek-praktek" negara-negara asing dalam melindungi hak kekayaan intelektual industri Amerika Serikat. Menurut Undang-undang dan sejarah legislatif, Special 301 adalah alatnegosiasi untukmemperbaiki praktek-praktek perdagangan pemerintah Amerika dengan para mitra dagangnya, yang memberi dampak negatif terhadap perlindungan hak kekayaan intelektual dan industri Amerika. Dengan tujuan untuk memilih negara-negara yang "tindakan, kebijakan atau praktekprakteknya dianggap sudah sangat serius" untuk dimasukan ke dalam daftar Priority Foreign Countries, yang ditargetkan untuk diambil tindakan khususs. 
(Hak Kekayaan Intelektual). Pada tahun 1985, IIPA (International Intellectual Property Alliance), yang terdiri dari 7 (tujuh) asosiasi perdagangan yang mewakili industri komputer, film, musik dan penerbit, menyampaikan laporan kepada Intemational Trade Commission of America, menggambarkan dampak dari pembajakan hak cipta kepada industri ini di sepuluh negara. Tujuh di antaranya adalah negara-negara Asia, seperti Indonesia, Malaysia, Filipina, Korea Selatan, Singpore, Thailand dan Taiwan. Laporan IIPA mengestimasi bahwa kerugian US $\$ 1,5$ milyar setahun sebagai akibat dari tidak layaknya Undang-Undang Hak Cipta yang berlaku di negara-negara tersebut.

Kongres Amerika ternyata dapat menerima keprihatinan dari perusahaanpenusahaan Amerika Serikat tersebut. Amerika Serikat memutuskan untuk mengambil tindakan, yang didasarkan pada dua alasan pokok, yang satu menyangkut isu ekonomi, dan yang lainnya menyangkut isu politik. Pertama, nilai HKI (Hak Kekayaan Intelektual) terhadap ekonomi Amerika Serikat telah meningkat secara signifikan. Untuk Hak Cipta saja, telah memberi kontribusi lebih dari US \$ 153 milyar, menguasai lebih dari 2 (dua) persen angkatan kerja, mempunyai surplus perdagangan lebih dari US\$12 milyar. Kedua, kebjjakan HKI yang agresif memperkenankan Kongres dan Presiden untuk memberi tanggapan terhadap tekanan politik yang diakibatkan oleh defisit perdagangan, tanpa harus mengambil tindakan proteksionisme.

Selama ini, Indonesia menempati posisi kedua dalam kategori Prionity Watch List setelah Cina, akibat tingginya kasus pembajakan kaset, compact disc, video compact disc, software komputer dan paten berkenaan dengan obat-obatan (pharmaceutical). Pada tahun 1997 saja, klaim karena pelanggaran $\mathrm{HKI}$ di Indonesia telah mencapai 668,2 juta dollar Amerika Serikat, di antaranya untuk pembajakan hak cipta sebesar 334,1 juta dollar Amerika Serikat, program komputer 256,1 juta dollar Amerika Serikat, serta untuk : pembajakan buku, film, rekaman lagu dan komposisi musik berjumlah 78 juta dollar Amerika Serikat. Ini belum termasuk pemalsuan merek dagang dari Amerika Serikat.

Berdasarkan data IIPA (Intemational Intellectual Property Alliance), tahun 1998 tingkat kerugian pembajakan hak cipta di indonesia berkisar 186 juta dollar Amerika Serikat. Namun, tahun 2000 turun menjadi 176 juta dollar Amerika Serikat. Dilihat dari nilai kerugiannya, pembajakan di Indonesia belum separah Cina, Korea Selatan, dan Malaysia, Cina yang berada pada peringkat pertama pembajakan hak cipta misalnya, telah merugikan pemilik hak cipta asing sampai satu milyar dollar Amerika Serikat pada tahun 1998 saja.

Pada tanggal 26 April 2002, Direktorat Jenderal Hak Kekayaan Intelektual, Departemen Kehakiman dan HAM baru saja. menyelenggarakan serangkaian acara, seperti Seminar untuk menyambut Hari HKI (Hak Kekayaan Intelektual) sedunia kedua. Penyelanggaran seminar yang berjudul WIPO National Seminar On New Emerging Issues On Copyrights diadakan pada tanggal 25 April 2002 di Hotel Menara Peninsula.

Namun, empat hari kemudian, Pemerintah Amerika Serikat memberi "hadiah" yang tidak mengenakan kepada Indonesia. Pada hari Selasa, 30 April 2002 di Washington, Amerika Serikat, melalui kepala Perwakilan Dagangnya (United States Trade Representative) Robert B. Zoellick mengumumkan bahwa 
Indonesia merupakan negara yang mendapat prioritas untuk diawasi (Priority Watch List) dalam masalah perlindungan HKI (Hak Kekayaan Intelektual). ${ }^{8}$

Dengan status Priority Watch List, pemerintah Amerika Serikat tidak melarang dan juga tidak menganjurkan investor Amerika Serikat untuk berinvestasi di negara-negara yang dikenai status demikian. Amerika tidak memberi jaminan terhadap investasi tersebut. Penilaian ini mencerminkan komitmen USTR (United State Trade Representative) terhadap perlindungan hak kekayaan intelektual di seluruh dunia. Perlindungan HKI (Hak Kekayaan Intelektual) seharusnya menjadi prioritas bagi negara-negara berkembang untuk dapat menarik investasi. Hal tersebut dikemukakan oleh Robert B Zoellick, Kepala Perwakilan Dagang Amerika Serikat. Dari laporan tahun 2002, Kantor Perwakilan Dagang Amerika Serikat memonitor 51 negara dalam dalam masalah periindungan $\mathrm{HKl}$ (Hak Kekayaan Intelektual). Dokumen USTR (United States Trade Representative) yang bejudul Report on Global Intellectual Property Protection menempatkan 15 negara dalam daftar Priority Watch List, Indonesia adalah salah satu dari 15 negara yang mendapat status Priority Watch List, tersebut, ke-15 negara tersebut, antara lain, Brasil, Dominika, Uni Eropa, Uruguay, Filipina, Mesir, Hongaria, Kolumbia, Lebanon dan Rusia, Israel, India, Taiwan dan lain-lain, sedangkan Cina, Thailand dan Malaysia yang juga kerap kali dituding sebagai surga pembajakan tidak masuk dalam daftar Priority Watch List.

\section{Akibat Kebijakan Section 3r} Pengaruhnya terhadap Ind...

Menurut data yang dikemukakan oleh IIPA (Intemational Intellectual Property Alliance), banyak negara baik di Asia, Amerika Latin maupun Eropa masuk dalam daftar Special 301, antara lain, Malaysia, Taiwan, indonesia, India, Filipina, Brasil, Dominika, Kolumbia, Rusia, dan Uni Eropa.

Jikalau Indonesia tidak dapat memperbaiki keadaan, maka sanksinya adalah penggunaan Special 301 yang ada pada United States Trade Act. Ketentuan ini memberikan mandat kepada pemerintah Amerika Serikat untuk melakukan pembalasan (retaliation) di bidang ekonomi terhadap Indonesia. Dalam hal ini, pasar Indonesia di Amerika Serikat yang menjadi taruhannya. Peringkat Priority Watch List dapat diubah, jika Indonesia benar-benar memerangi pembajakan produk-produk yang berkandung HKI (Hak Kekayaan Intelektual).

Bagi Indonesia, persoalannya bukan sekedar tuduhan Amerika Serikat itu benar atau tidak. Namun harus diakui, keluhan utama para investor Amerika Serikat, adalah belum memadainya penegakan hukum di Indonesia.

Dalam hal invenstasi, pemerintah Amerika Serikat tidak mau melakukan invenstasi di negara-negara yang masuk dalam daftar Priority Watch List, serta menganjurkan para pengusahanya agar tidak berinvestasi di negara-negara yang dimasukan ke dalam daftar tersebut seperti indonesia. Namun, jika tetap juga ingin berinvestasi, pemerintah Amerika Serikat memang tidak melarang,

${ }^{8}$ Bisnis Indonesia, 7 Mei 2002. 
tetapi tidak ada jaminan dari pemerintah Amerika Serikat.

Namun demikian, peringkat atau status Priority Watch List dapat berubah, apabila pemerintah Indonesia secara intensif melobi pihak Amerika Serikat dengan memberi penjelasan bahwa Indonesia sekarang sudah serius memberantas pembajakan HKI. ${ }^{9}$

IIPA (Intemational Intellectual Property Alliance) terus memonitor perkembangan Indonesia sejak 1985. IIPA (intemational Intellectual Property Alliance) menamakan Indonesia sebagai negara pembajak terburuk kedua di Asia. Pada tahun 1987, setelah ada petisi yang diajukan oleh IIPA untuk membatalkan kemanfaatan dan kemudahan GSP (Generalized System of Preference) kepada Indonesia, kemudian Indonesia memberlakukan UndangUndang Hak Cipta yang lebih maju dan lebih baik. GSP (Generalized System of Preferences), adalah pemberian fasilitas pembebasan bea masuk oleh Amerika Serikat.

Indonesia dewasa ini, telah berpartisipasi dalam program GSP (Generalized System of Preferences). Suatu program perdagangan Amerika Serikat yang memperkenankan pembebasan bea cukai dari negara-negara berkembang tehadap produk-produk tertentu ke wilayah Amerika Serikat. Pada 11 (sebelas) bulan pertama tahun 2001, barang-barang buatan Indonesia yang bernilai US\$1.2 milyar (atau ekuivalen $13.2 \%$ dari total impor Indonesia ke Amerika Serikat), yang masuk ke Amerika Serikat dengan bebas bea masuk di bawah program GSP (Generalized System of Preferences). Untuk dapat mencapai syarat-syarat kemudahan perdagangan (trade preferences) yang diberikan secara sepihak, maka negara yang bersangkutan harus memenuhi berbagai kriteria yang ditentukan oleh United States Trade Representative tersebut, antara lain, ialah apakah negara yang bersangkutan telah memberikan "perlindungan hak kekayaan, intelektual secara layak dan efektif" terhadap" produk-produk buatan Amerika Serikat. Ketidak berhasilan Indonesia untuk memberantas secara efektif pembajakan hak cipta, dapat menimbulkan masalah serius tentang apakah negara Indonesia telah memenuhi kriteria sebagaimana ditetapkan sebagai kelanjutan adanya perlakuan yang istimewa dan menguntungkan berdasarkan program GSP (Generalized System of Preferences). Pada tahun 1989, Indonesia mengadakan perjanjian hak cipta bilateral dengan Amerika Serikat. Karya-karya cipta Amerika Serikat dan produk-produk dan rekaman suara mendapatkan perlindungan hukum di Indonesia. Meskipun pemerintah Indonesia telah berinisiatif untuk menyapu bersih pembajakan audio sejak tahun 1988, dan upaya ini telah memperoleh kemajuan besar dalam rangka melawan pembajakan video kaset pada tahun 1991-1992, namun, Indonesia tetap berada pada peringkat watch list. Dari tahun 1989 sampai 1995, pembajakan buku-buku dan perangkat lunak Amerika Serikat semakin meningkat. Indonesia tetap berada pada posisi Priority Watch List sampai 1999.

Mengingat pembajakan HKI (Hak Kekayaan Intelektual) di Indonesia yang dianggap semakin merajalela, pada tahun 2000, IIPA (Intemational Intellectual Property Alliance), memberi rekomendasi agar Indonesia

甲/bid. 
di-upgrade ke posisi Watch List. Hal ini disebabkan oleh adanya kondisi di mana liberalisasi pasar, anti pembajakan, dan upayaupaya perbaikan terhadap Undang-Undang Hak Cipta harus diteruskan di Indonesia. Dengan persetujuan USTR (United States Trade Representative), Indonesia masuk ke peringkat Watch List pada tahun 2000 . Namun, pada tahun 2001, demikian juga pada tahun 2002, Intemational Intellectual Property Alliance merekomendasikan kepada Departemen Perdagangan Amerika Serikat dan WIPO (World Intellectual Property Organization) untuk tetap memasukkan Indonesia ke peringkat Priority Watch List. USTR setuju, dengan merujuk pada pengumuman Special 301 tanggal 20 April 2001, yang menyatakan bahwa "tingkat pembajakan di pasar Indonesia yang begitu luas terhadap hak cipta dan barang-barang mereka merupakan yang tertinggi di dunia".

Ancaman tindakan balasan juga datang dari Eropa. Berdasarkan Peraturan (EC) 2641/ 84 dari Council of the European Communities, tindakan perdagangan dapat dilakukan terhadap negara-negara ketiga atas dasar praktek-praktek perdagangan tidak sehat (unfair trade practices) di negara-negara tersebut. Berdasarkan Peraturan ini, IFPI (Intemational of Phonogram and Videogram Producers) menyampaikan klaim kepada European Commission. Komisi ini memutuskan bahwa terdapat bukti yang cukup untuk membenarkan dibukanya penyelidikan. Klaim ini menyatakan bahwa Indonesia tidak memberi perlindungan yang efektif dalam menghadapi reproduksi rekaman suara ilegal, dan kegagalan ini telah menstimulasi untuk membuat rekamanrekaman suara bajakan dalam jumlah yang besar. Sementara itu, Komisi memutuskan untuk menangguhkan proses pemeriksaan sampai 29 Pebruari 1988, mengingat fakta bahwa Indonesia telah menyetujui Amandemen Undang-Undang Hak Cipta No. 6 Tahun 1982, dan Indonesia telah memberitahu kepada Komisi untuk mengadakan negosiasi guna mencari solusi untuk memberikan perlindungan yang sama atas karya-karya asing sebagaimana yang diberikan kepada warganegara Indonesia. Indonesia mendapat ancaman pencabutan GSP (Generalized System of Preferences) yang dikaitkan dengan pembajakan rekaman video dan kaset lagu. IFPI (Intemational Phonograms and Videogram Producers) menuntut MEE (Masyarakat Ekonomi Eropa) agar memaksa pemerintah Indonesia untuk segera melancarkan perlindungan hak cipta secara menyeluruh, kalau tidak, MEE (Masyarakat Ekonomi Eropa) diminta memberikan sanksi perdagangan, yang mencakup, antara lain, membatasi impor barang dari Indonesia. Menurut David Laing, juru bicara IFPI (Intemational Phonograms and Videogram Producers), pembajakan rekaman video dan kaset lagu semakin meningkat di Indonesia, sedangkan pemerintah Indonesia tetap saja membiarkan keadaan dan situasi ini terus berlangsung, malah memungut pajak dari kaset-kaset bajakan itu. Tudingan dan tuduhan ini terutama ditujukan kepada Jackson Record di Jakarta, sebagai salah satu perusahaan yang merekam lagu-lagu vidio dan kaset, kemudian menggandakannya secara besar-besaran. Wakil Direktur IFPI ( $n$ temational Phonograms and Videogram Producers) Asia, Kasin Cha Tong mengungkapkan bahwa kerugian industri rekaman Eropa karena kaset bajakan Indonesia, paling sedikit US\$ 150 juta. Menurut Kasin, atas permintaan IIPA (Intermational Intellectual Property Alli- 
ance), Amerika Serikat telah mengancam pencabutan hak perdagangan istimewa di bawah program GSP (Generalized System of Preferences) bila Indonesia tidak menerapkan perlindungan hak cipta sepenuhnya atau selambat-lambatnya pada Oktober 1987.

Pada April 1988, ada surat perjanjian yang ditandatangani oleh Duta Besar Atmono, wakil Indonesia untuk Kerajaan Belgia dan Willy de Clereg, perutusan MEE (Masyarakat Ekonomi Eropa) untuk para pengusaha Indonesia rekaman kaset lagu-lagu Barat di Indonesia. Mulai bulan itu juga pengusaha kaset Indonesia tidak lagi diperkenankan menggandakan kaset-kaset Barat tanpa ijin pemegang hak cipta, terutama dari negara-negara anggota MEE (Masyarakat Ekonomi Eropa).

\section{Simpulan}

Banyaknya kasus pelanggaran HKI (Hak Kekayaan Intelektual) di Indonesia, jika tidak ditangani segera, dikhawatirkan selain dapat mengancam reputasi Indonesia di mata dunia intemasional, juga akan menghambat masuknya investasi. Sebaliknya, juga akan menyulitkan ekspor produk-produk buatan Indonesia terutama tekstil dan garmen ke manca negara.

Sebagai negara berkembang, jika ada tuduhan bahwa Indonesia termasuk negara yang masih lemah dalam penegakan HKI (Hak Kekayaan Intelektual) adalah sebagai hal yang wajar. Hal ini juga terjadi pada negara lain seperti Cina, yang membajak software buatan Amerika Serikat, sehingga Amerika Serikat menekan Cina dengan berbagai alasan, bahkan sampai ke pembalasan (retaliation).

Di bawah ini adalah daftar negara-negara yang dimasukan ke dalam Daftar Special 301 oleh IIPA untuk tahun 2002:

\begin{tabular}{|c|c|c|}
\hline $\begin{array}{l}\text { Priorthy Forolgn Country } \\
\text { Ukraine } \\
\text { Priority Watch Ulst } \\
\text { Argentina } \\
\text { Brazi } \\
\text { Colombia } \\
\text { Doninican Republic } \\
\text { Egypt } \\
\text { European Union } \\
\text { Hungary } \\
\text { India } \\
\text { Indonesia y } \\
\text { Israel } \\
\text { Lebanon } \\
\text { Philippines } \\
\text { Russia } \\
\text { Taivan } \\
\text { Unuguay }\end{array}$ & $\begin{array}{l}\text { Watch Lst } \\
\text { Armenia } \\
\text { Azertajan } \\
\text { Bahamas } \\
\text { Belarus } \\
\text { Bolivia } \\
\text { Canada } \\
\text { Chile } \\
\text { Costa Rica } \\
\text { Greece } \\
\text { Guatemala } \\
\text { Italy } \\
\text { Jamaica } \\
\text { Kazakhstan } \\
\text { Korea } \\
\text { Kunwait } \\
\text { Latvia } \\
\text { Lithuania } \\
\text { Malaysia }\end{array}$ & $\begin{array}{l}\text { New Zealand } \\
\text { Pakistan } \\
\text { Peru } \\
\text { Poland } \\
\text { Qatar } \\
\text { Romania } \\
\text { Saudi Arabia } \\
\text { Slovak Republic } \\
\text { Taijikstan } \\
\text { Thiland } \\
\text { Turkey } \\
\text { Turknenistan } \\
\text { Uthekistan } \\
\text { Venezuela } \\
\text { Vietram } \\
\\
\text { Section } 306 \text { Monltoring } \\
\text { China } \\
\text { Paraguay }\end{array}$ \\
\hline
\end{tabular}

- Intellectual Property Law Joumal, Volume 16, Number 6, June 2002 


\section{Daftar Pustaka}

Charles Gilie. "New Copyright Law of IndonesiaImplications for Foreign Investment," 4 EIPR, (1988).

Elizabeth Chien -Hale. "Asserting U.S. Intellectual Property Rights In China : Expansion of. Extraterritorial Jurisdiction?," Joumal, Copyright Society of the U.S.A., Vol, 39, No. 1, (Fall 1991).

International Intellectual Property Alliance. 2002 Special Report, Indonesia Executive Summary, 2002.

IP ASIA. Intellectual Property, Marketing and Communications Law, Vol. 9, No. 9, (November 1996).

Joseph Pandy. Pilih Berantas Mafia Pelanggaran HAKI dan Kita Menghadapi Hambatan Atas Masuknya Investasi Kesini. Jakarta: Pertimpunan Masyarakat HAKI Indonesia (Indonesia Intellectual Property Society), 2001.

Kompas. 12 Juli 2000; 16 April 2002; 2 Mei

- 2002; 6 Agustus 1999; 4 Mei 2000; 9 Maret 2000.
Loyola of Los Angeles. Intemational \& Comparative Law Joumal, Vol. 18, No. 3 , June 1996.

Media Indonesia. 7 Mei 2002.

Michael Blakeney. "The Impact of the TRIPs Agreement in the Asia Pacific Region", EIPR, 1996.

Omnibus Trade and Competitiveness Act of 1988.

Simon Frith. Music and Copyright. Edinburgh University Press, 1993.

Suara Pembaruan. 19 Juli 2000; 21 April 2002.

Tempo. 25 April 1987; 4 Juni 1988.

The International Intellectual Property Alliance. "Piracy of US Copyrighted Works in Ten Selected Countries: A Report by the International Intellectual Property Alliance to the United States Trade Representative, 1985.

Intellectual Property Law Journal, Volume 16, Number 6, June 2002. 